\title{
Inhibitors and Enablers of Mobile Data Services Use in South Africa
}

\author{
Hiranjali Ramburn and Jean-Paul Van Belle
}

Department of Information Systems, University of Cape Town, South Africa

\begin{abstract}
The uptake of advanced mobile data services in South Africa has been slow, even though it is currently the largest cellular market and has one of the most advanced mobile telecommunication industries in Africa. This apparent contradiction forms the subject of this article. It presents the findings from a survey in South Africa that looked at the adoption of a number of data services, including content services, web browsing, email, MMS, mobile games, mobile banking and mobile chats. It was found that, apart from SMS, users were indeed generally slow to adopt any of the 3G data services. The article lists and discusses the major obstacles and inhibitors to this adoption as mentioned by the respondents. It also reports on what mobile users perceived could be done to promote the adoption of mobile services. This research should, therefore, provide useful insights to researchers interested in mobile technology adoption in Africa as well as the providers of mobile data services.
\end{abstract}

Keywords: Mobile Data Service adoption, inhibitors and enablers of Mobile Data Services, Mobile Internet, South Africa

\section{Introduction}

The mobile phone, or cell phone as it is commonly called in Africa, is now regarded as a ubiquitous multipurpose communication and computing device, with penetration rates of above $90 \%$ of South Africa's population. New functionalities, ranging from internet access to mobile television, are constantly added to the basic data access function of these devices (Tarasewich, 2003).

There has been a lot of excitement about the use of mobile data services and mobile commerce in African countries over the past few years, with claims that mobile commerce would become the next new trend in the electronic marketplace (Joubert \& Van Belle, 2009).

Mobile Commerce, more commonly referred to as $\mathrm{M}$-commerce, is defined here as the use of wireless handheld devices such as cell phones to conduct commercial and financial transactions (Pinheiro, 2003).

However, M-commerce cannot fulfil its potential without the widespread acceptance of mobile data services (Massey, Ramesh \& Venkatesh, 2003; Mattila, 2004). Despite huge investments in the sector, the actual adoption and use of mobile data services in most African countries has been particularly slow when compared to countries such as Japan, Taiwan, USA and UK. In Africa, the use of SMS and chat services has been widely accepted, but people are still reluctant to engage in other mobile data services, such as MMS, mobile banking and web browsing amongst others (Brown, Gordon, Janik \& Meyer, 2005). Thus, any barriers to the adoption of mobile data services is an essential concern for M-commerce stakeholders, as are possible enablers to speed user adoption.

Copyright (C) 2011 Hiranjali Ramburn,and Jean-Paul Van Belle. This is an open access article distributed under the Creative Commons Attribution License unported 3.0, which permits unrestricted use, distribution, and reproduction in any medium, provided that original work is properly cited. Contact author: Hiranjali Ramburn E-mail: ranjali17@gmail.com 


\section{Research Objective}

We first investigate the extent to which mobile data services have been adopted in Mauritius. The reasons why mobile phone users are reluctant to use different data services and the key inhibitors are explored. Lastly, the factors, which may encourage users to use mobile data services more frequently, are discussed.

The research focused on individual, not business users of mobile data services in South Africa. Given the technological landscape, only the following mobile data services were considered: cell phone banking, downloading ring tones, games and logos, downloading content such as weather, sport and/or news, web browsing, accessing email, mobile gaming/video, short messaging service (SMS), multimedia messaging (MMS) and online chats such as MSN messenger and Mxit.

These services were selected since they form part of the most popular and advanced mobile data services available in South Africa. We chose to conduct this study in South Africa because it already has the required infrastructure for new mobile technologies and services in place, thus, the economy of the country could experience a major boost with the adoption and use of mobile data services (Rouvinen, 2004). The progress of the mobile telecommunication industries depends on not only the development of mobile technology and the data services provided, but also the subsequent adoption of the services by the consumers (Bouwman, Carlsson, MolinaCastillo \& Walden, 2007). Hence, the necessity to investigate the potential barriers and factors which may encourage potential and existing users to adopt and/or continue use of mobile data services.

The results of this research will be of value to M-commerce stakeholders. Although the mobile industry is currently one of the fastest growing markets in South Africa, consumers are still reluctant to use and adopt the new services being introduced. Therefore, this research allows the stakeholders to better understand the consumer market of mobile data services by providing them with an insight into the potential barriers which discourage current and future use, as well as how these might be alleviated. Researchers in the field of Mobile Communications should be interested in the enablers and inhibitors as described and may wish to compare this across time or geographic dimensions.

\section{Definitions and Prior Research}

\section{Definitions}

Mobile data services are here defined as wireless access to a set of B2C activities using a mobile phone available through mobile service providers (Wang \& Lin, 2006; WMIS, 2006 as cited by Oh et al., 2006). Examples include transactions, such as SMS, send/receive emails, MMS, mobile games, content services, mobile banking, etickets, mobile auctions and stock trading. Some studies have used mobile data services, mobile applications/services or even mobile Internet services interchangeably (Bouwman, Carlsson, Molina-Castillo \& Walden, 2007).

This research focuses on the use of mobile phones as opposed to Personal Digital Assistants (PDAs). This is an important distinction to note, since PDAs are mostly used by corporate users for business transactions while mobile phones are mainly utilised for individual use (Singh, 2003). It must be noted that the difference between mobile phones and PDAs is gradually becoming less apparent as the screen sizes on phones get larger, with applications being continuously added. "However, the main difference is still the numeric keypad and one-hand usage of most phones as opposed to the touch screens and two-hand usage of most PDAs" (Kaasinen, 2005).

\section{The Mobile Telecommunication Industry in South Africa}

Although Africa accounts for $13 \%$ of the world's population, it only accounted for $2.3 \%$ of the world's (fixed line and cellular) telephonic subscribers at the end of 2002 (Marrakech, 2002). However, over the last few years, many African countries have witnessed rapid developments of their mobile networks and infrastructure, with 
the number of mobile subscribers increasing at 35\% a year. This has resulted in an increase in tele-densities and better reach and service to people from the rural areas (Scott, Batchelor, Ridley \& Jorgensen, 2004). South Africa has one of the most sophisticated telecommunication systems of all emerging markets and ranks $23^{\text {rd }}$ in telecommunications development (Manjoo \& Kankwenda, 2007). The telecommunication sector contributes approximately $6 \%$ to South Africa's GDP (E- Business Handbook, 2005). One of the most remarkable occurrences within the South African telecommunication environment has been the rapid adoption rate of mobile phones (Van Wyk \& Van Belle, 2005). As at the end of December 2008, the South African market consisted of approximately 47.28 million mobile subscribers (Business Monitor International, 2009). This is a significant increase in the number of mobile users when compared to the reported 38 million estimated in 2006. Furthermore, with more than $83 \%$ of the South African population currently using mobile devices, South Africa is the largest cellular market on the African continent, which holds around 78 million cellular users (Converging Communications, 2005).

The South African mobile industry operates under a unique 3-tier model (Manjoo \& Kankwenda, 2007). The 3 main stakeholders are the Mobile Network Operators (MNOs), Service Providers (SPs) and Wireless Application Service Providers (WASPs). Although South Africa has four MNOs, namely Vodacom, MTN, Cell C and Virgin Mobile, the first two dominate the market and together, hold about 90\% market share (Business Monitor International, 2009). Service Providers (SPs) are in charge of the retailing of mobile products (contracts, handsets, prepaid vouchers and data services) to the general public and corporate users. They are also responsible to manage customer relationship on behalf of MNOs. Wireless Application Service Providers (WASPs) are responsible for the creation, promotion and hosting of mobile services. They depend on both SPs and MNOs to provide the infrastructure and customer relationship to offer their services.
Some researchers believe that this 3-tier model poses a serious threat for $M$ commerce in South Africa as WASPs are less motivated to introduce more services since profits have to be split in three ways (Vechattio, 2005). Some studies established that while consumers trust MNOs, they are not confident of the services offered by WASPs and in the past, some WASPs were held responsible for misleading advertising; billing consumers for services not received; charging very high rates and SPAM (Joubert \& Van Belle, 2009). However, other researchers have attributed the success of mobile phones and data services to this unique 3-tier model (Hislop, 2004).

\section{Mobile Data Services in South Africa}

South Africa was quick to make significant financial investments for both the purchase of 3G licenses and rollout of 3G network infrastructure. Vodacom was first to launch 3G services in December 2004 followed by MTN. Currently, both Vodacom and MTN users who are equipped with $3 \mathrm{G}$ enabled handsets can make video calls (Joubert \& Van Belle, 2009). In March 2006, MTN launched 3.5G technologies, which make use of High Speed Downlink Packet Access (HSDPA) to provide users with connection speeds of 2 Mbps. Vodacom followed in April 2006 (Global UMTS Network Rollout Status, 2006) .

Despite the fact that the use of mobile devices is the fastest growing technology ever seen in South Africa, the use of advanced mobile data services has still not touched the lives of most cellular phone users (Goldstuck, 2005). The major portion of the population uses SMS, chat services and some leisure based services such as ring tones and games but they are still reluctant to engage in other more advanced data services (Scott et al., 2004; Goldstuck, 2005).

\section{Enablers and Inhibitors of Mobile Data Services}

Mobility, convenience and ubiquity are the main benefits of using mobile data services. Internet now travels with the customers; transactions can be conducted from any 
location and at any time of the day, which makes it well suited for the customers. Information can now be easily accessed at anytime from any location hence ensuring convenience, mobility and ubiquity (Turban et al., 2002).

However, the actual usability and security of mobile devices have been debated. While some people find using mobile devices to conduct transactions relatively easy, others experience difficulty with the small screen size and small keypad. Data input becomes a problem, and this can lead to wasted time, errors and frustration experienced by users, hence making usability less attractive (Tarasewich, 2003; Chen \& Frolick, 2004).

Some researchers believe mobile commerce has fewer security flaws as opposed to electronic commerce as the mobile device travels with the user, hence giving the latter a greater sense of security (Brown et al., 2005; Doens, 2005). However, the mobility of these mobile devices also increases the risk of losing them (Tarasewich, 2003). Mobile users are worried about the safety of their devices as these can easily be lost or stolen. One of the key concerns which emerged during the results analysis of a South African study was: "Although cell phone banking is convenient and more secure in a way, it would be more inconvenient if one loses the phone, because everything will have to be replaced" (Gordon, Janik \& Meyer, 2004).

On the downside of the use of mobile data services, information security is a potential concern. Information security refers to the safety and security of data as it travels over the network. Concerns have been expressed about the call being intercepted and decrypted (Gordon et al., 2004). Despite technical assurances to the contrary, security perceptions remain negative among many users.

Cost of mobile data services is another prominent inhibitor. It is one of the major factors to be considered by consumers when deciding whether or not to use a technology or service. Most consumers perceive the cost of mobile data services to be particularly high (Gordon et al., 2004).
Mobile phone charges in South Africa are believed to be up to10 times more expensive than that of other comparable European countries (Steenkamp, 2005).

Other factors inhibiting use of mobile data services include lack of business requirements, incompatibility of handsets, lack of skills and knowledge concerning the service and poor design interface of the devices (Singh, 2003).

\section{Research Methodology}

One of the research objectives was to assess the relative extent to which the various mobile data services have been adopted in South Africa. The main focus of this research, however, is the understanding of factors which act as barriers to the adoption and use of mobile data services followed by an overview of the major inhibitors and thereafter the factors which will subsequently encourage adoption and use. For this purpose, we adopted a positivist, quantitative research approach by sending a questionnaire to a sample of mobile phone users. The research is mainly descriptive in nature. A cross-sectional time horizon was chosen because of the constant evolutionary nature of mobile data services and mobile technologies: new mobile data services are introduced at a very rapid pace.

The questionnaire first measured the current, previous and future level of use of respondents by focusing on both the variety and frequency of the use of the above mentioned mobile data services. The respondents were then prompted to state the reason(s) why they are not using any of the mobile data services. A final section asked respondents to rank the three most influential factors which they believe will inhibit or encourage their use. A stratified sampling approach with sub-groups based on age, occupation and income have been investigated.

We selected a first select sub-sample in South Africa consisting of university students and staff. Students, in particular, can be seen as an interesting population group because they are young, innovative, sophisticated and well-networked users who are familiar with the mobile 
technology, accounting for some of the key adoption factors in traditional adoption models. A second sub-sample came from the business environment where people are thought to achieve direct financial and time efficiencies from using the technologies. This sample is deemed to be suitable for the purpose of this research as the participants represent different background and socio-economic status. The sample is mostly from the Western Cape. Even though this may be fairly representative for South Africa in terms of income and age, it is not fully representative of the country's population in terms of other social demographics such as race, language, or culture. This bias, which may or may not affect the findings, is a limitation of this study but was forced on the researchers because of practical feasibility and resource constraints.

A pilot study was initially conducted. The questionnaires were distributed to a subset of the above described sample. The pilot study allowed the researcher to uncover whether the questionnaire was userfriendly, clear and understandable to the intended sample. Based on the feedback received, the questionnaire was reviewed and refined.

The modified questionnaires were then delivered to the respective samples. The researcher first made some initial contact with a few targeted respondents in order to encourage greater participation of the respective samples, hence ensuring a higher response rate. Some questionnaires were hand-delivered by the researcher, while others were sent via internal mail. 247 questionnaires were obtained but 35 of them were inappropriate to be used for the analysis, resulting in 212 usable responses. These samples are sufficiently large to provide reasonably reliable data.

\section{Demographic Analysis}

The sample consists of 128 (60\%) males and $84(40 \%)$ females. With respect to the age distribution, the sample reflects a relatively young user group: more than $40 \%$ of the respondents fall in the 21-25 year age group. This percentage reflects the stratified sampling approach which targeted students as one of two desired population groups. Only $8-9 \%$ of the sample is older than 40 years. Although people above 40 years old have been targeted, they were either very reluctant to fill in questionnaires or they did not use any of the mobile data services provided. Occupation is another important demographic factor. The target sample comprises of $53 \%$ students and $47 \%$ of working people. The latter consisted of academics, analysts, programmers and software developers, accountants, researchers, administrators, sales people and marketing executives.

\section{Usage Profile}

This section discusses the usage profile of the various mobile data services. Not surprisingly, SMS is the most frequently used service with $98 \%$ of sample using it. MMS and web browsing are the most sought after services after SMS, followed by online chats and downloading of content. $37 \%$ of the sample access email from their mobile phones while $31 \%$ use top up services and $30 \%$ download ringtones from their mobiles. Cell phone banking and playing online games are the least popular services with more than $80 \%$ of the sample not using these 2 services at all. As for frequency of use, $67 \%$ of the sample use SMS several times and $17 \%$ engage in web browsing. $11 \%$ use online chats several times daily while only $9 \%$ use email several times daily. Very few respondents use the other services more than once daily. Figure 1 below shows the distribution. 


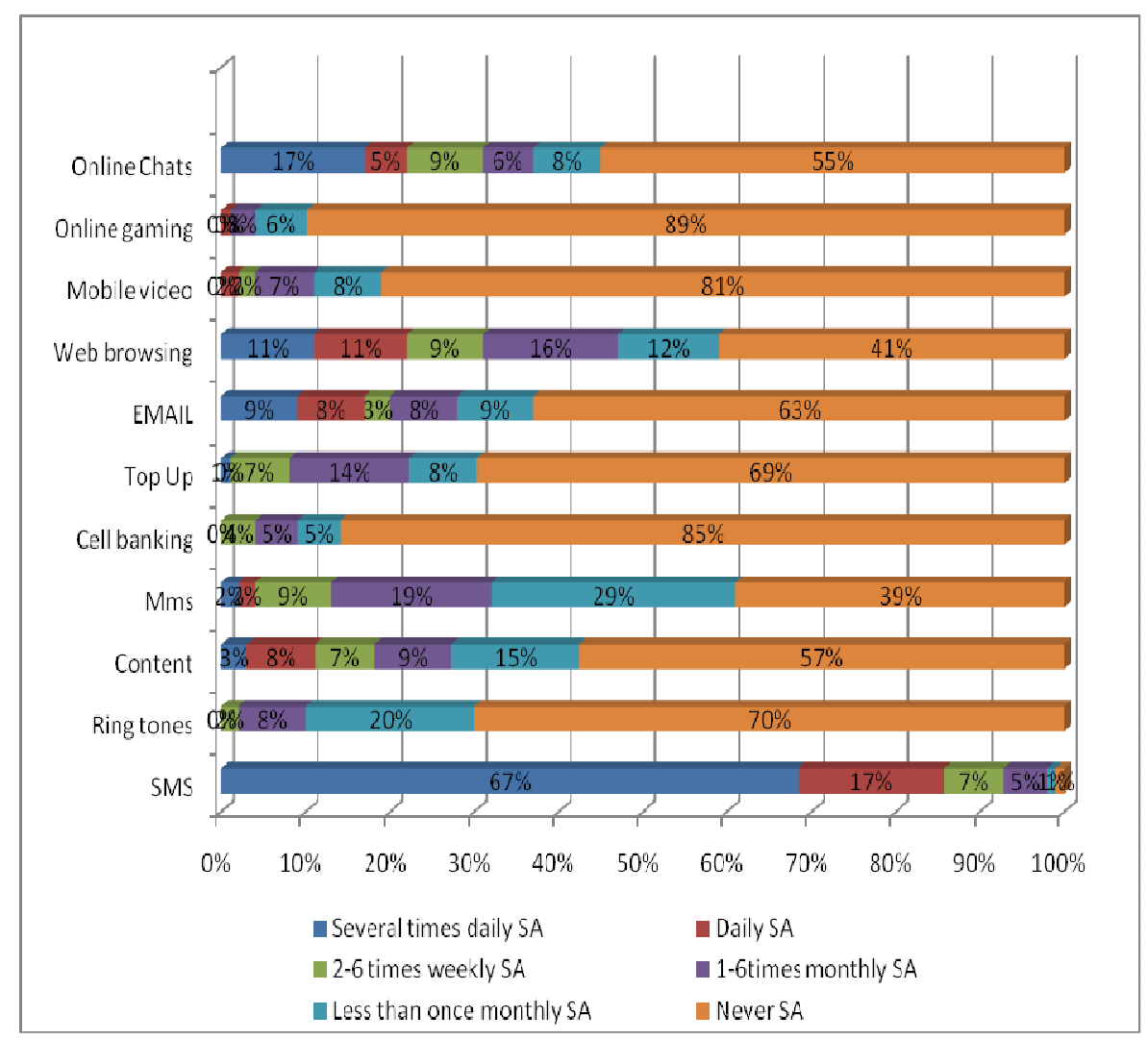

Figure 1: Frequency of Use of Mobile Data Services

This frequency distribution provides an indication of the services which have been successfully accepted in South Africa. As discussed in the literature, this research reveals that SMS and chats are the most popular services in South Africa. Web browsing, MMS and content services have gained relative acceptance amongst users. The results give mobile stakeholders an insight on the services which have not been widely adopted as yet, allowing them to market the services better in an attempt to increase awareness and generate curiosity.

This usage trend is comparable to other African countries with similar technological infrastructure as well. For instance, Mauritius follows a similar pattern for services such as SMS, downloading of content and cell phone banking, with SMS being the most popular service in Mauritius as well. Some differences can however be noted in the usage trends of MMS, web browsing, email, top up and online chats. Whilst MMS, web browsing and email are highly used services in South Africa, very few Mauritians are currently using them (Ramburn, 2007)

\section{The Major Reasons Accounting For Non- Use of Mobile Data Services}

In order to identify the barriers to pervasive adoption of mobile data services, respondents were asked to state reasons for not using data services in an open response field. These were classified by the researchers into categories. This procedure allowed us to gain richer insights with regards to respondents' perceptions of what is preventing them from using the various available mobile data services. Respondents unanimously cite the lack of need for the services as the main reason accounting for non-use of mobile data services. Lack of interest in the services, high cost of transactions and lack of awareness then follow. However, not all of the reasons that are advanced for nonadoption can be seen as inhibitors: lack of need or awareness is not primary inhibitors (though, admittedly, focused 
marketing can address both by creating a real or perceived need).

\section{The Major Inhibitors of Mobile Data Services}

In this section, we attempted to identify the factors which respondents' rate as prime inhibitors and for this purpose, each inhibitor has been grouped in three categories namely; the number of times respondents rated them as the $1 \mathrm{st}$, 2 nd or 3rd most significant inhibitors. Key inhibitors to adoption were culled from the literature and users were asked to identify and rank their top three inhibitors. Figure 2 below illustrates the findings.

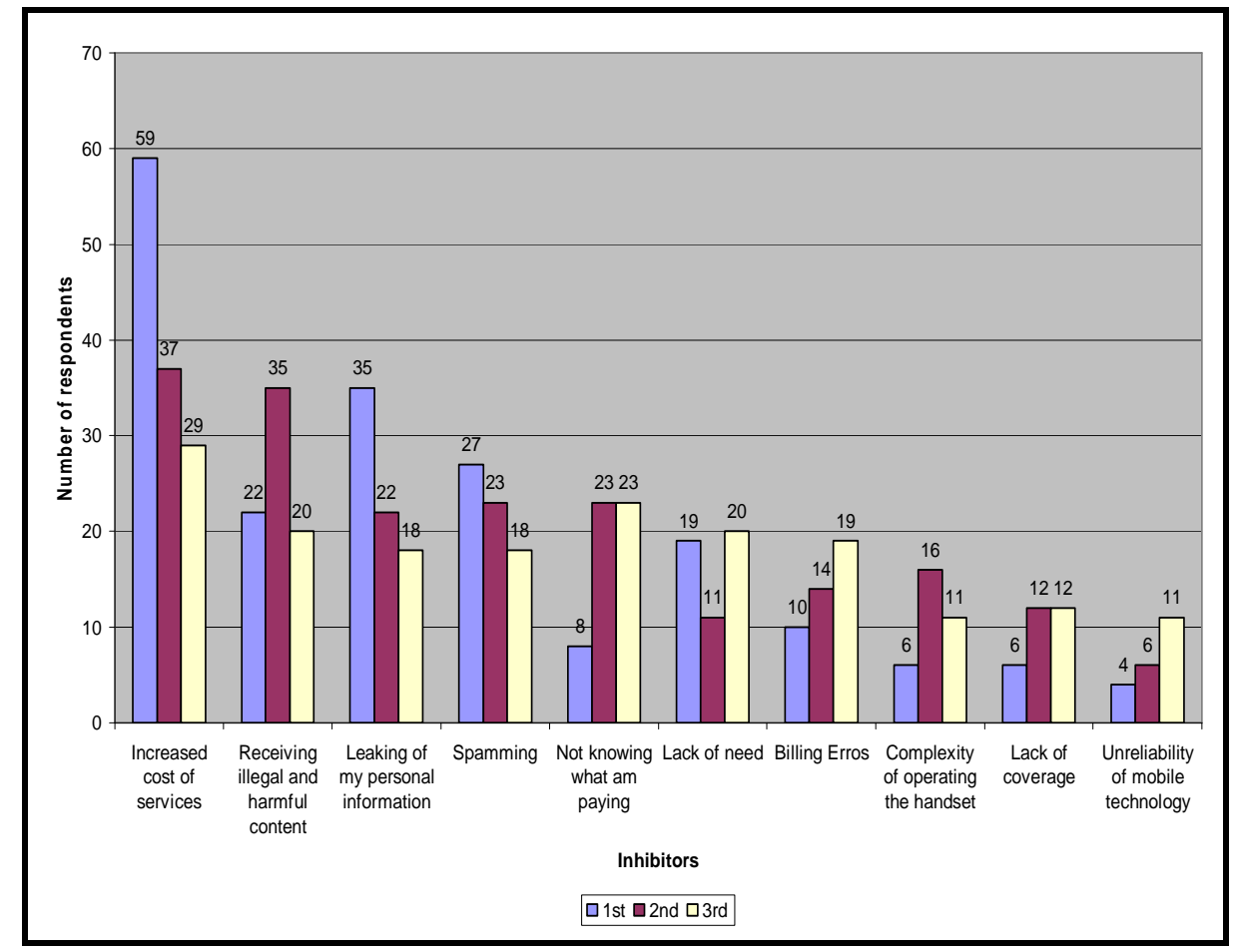

Figure 2: Inhibitors of Mobile Data Services in South Africa

Increased costs, leaking of personal information and spamming are seen as the most prominent inhibitors. Receiving illegal harmful content, lack of need of services, billing errors and lack of knowledge on the cost of services closely follow.

Increased cost of transaction is seen as the most potential inhibitor. This result is consistent with the findings of Ramburn (2007) who interviewed a sample of mobile data users in South Africa to better understand the reasons accounting for non use. The sample unanimously agreed that they will cease use of mobile data services, should the price of services increase. Moreover, mobile data services users find services such as ring tones, MMS and online games, where they have to subscribe to the service provider, still very expensive while services such as chats, cell phone banking and email, where they only pay for the data usage fee, relatively cheaper. They also mention that if costs of these services are reduced, people will be encouraged to use them more frequently. For instance, some useful services such as 'Look4me' provided by Vodacom, despite being very beneficial and useful, are not yet affordable to the average mobile user (Ramburn, 2007). This can be a possible reason to explain why our above findings showed SMS, chat and emails as the extensively used services whilst ringtones online games were less popular. 
The research found while respondents are apprehensive to use services such as mobile banking due to the fear of fraud, those who do use it will immediately stop usage, should they lose any confidential information. With regards to spamming, mobile data users do not welcome advertisements that are not focused on mobile products and services. They see this practice as being distracting and frustrating, contributing towards decreasing the value derived from using these services thus acting as a potential inhibitor.

\section{The Major Factors Encouraging Use of Mobile Data Services}

The final part of this paper provides an insight into the most significant factors promoting or encouraging the use of mobile data services. The same method as above has been used to reveal the factors users rate as most important. The first two major factors influencing use of mobile data services are lower prices of services and a wider range of services followed by increased awareness of new services and better reliability of services.

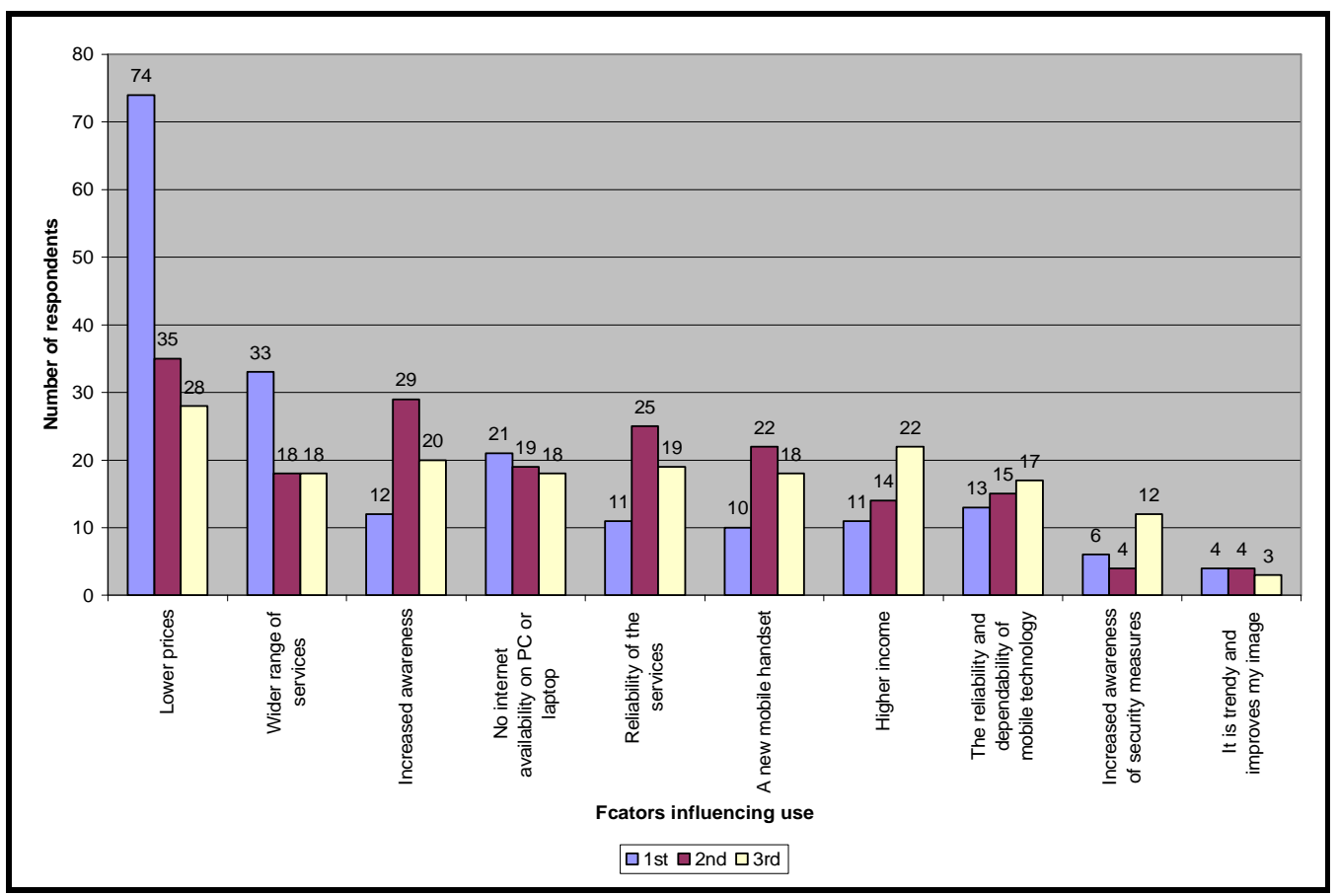

\section{Figure 3: Major Factors Encouraging the Use of Mobile Data Services in South Africa}

The influential impact of cost as both a determinant and inhibitor of mobile data services stand out clearly. This factor is often not given prominence in the research in developed countries. Some of the mobile data services are still relatively expensive, especially when compared to non-African countries. The high cost combined with the relatively lower income - these can be taken together as "affordability" - appear to reduce usage of important services and stop further usage of entertainment-based services. Conversely, lower-priced services are deemed to a major incentive promoting trialability of new services. Next, a wider range of services, allowing respondents to be more functionally efficient, would encourage them to engage in more frequent use of mobile data services. Lastly, increased awareness of mobile data services is a distinguished factor that may encourage trial ability and continued use.

\section{Conclusions and Implications}

This research reports on a survey that looked at the use and adoption of a number of data services, namely SMS, downloading 
of ringtones, content services, web browsing, email, MMS, mobile games, mobile banking and mobile chats. South Africa has an advanced mobile telecommunication industry and boasts a high penetration rate with more than $83 \%$ of the South African population currently uses mobile phones. However, the advanced mobile data services which have been introduced in the last few years have not been adopted by most mobile subscribers. To investigate why (not), a sample of more than 247 respondents was obtained to look at the use of mobile data services and the main inhibitors. Apart from SMS, the most popular data services in South Africa were MMS, web browsing, emails and online chats.

The main inhibitors of mobile data services are mostly cost-related and include the high cost of transactions, billing errors and lack of visibility of transaction costs. Other prominent inhibitors include reception of harmful content, leakage of personal information, spamming and lack of (perceived) need of the services. Lower prices of transactions, a wider range of services and increased awareness were cited as the major factors influencing use of mobile data services.

This research leads to a number of practical recommendations. Cost appeared to exert a strong inhibiting impact on use. Consequently, the cost of a number of services should be lowered to boost up use of mobile data services. New services should be introduced at a relatively low price for a specific time period to promote trialability. Additionally, increased transparency with regards to the billing and cost of some transactions is essential. Finally, since lack of awareness was also a major issue, better advertising or specific promotional campaigns could increase consumer awareness about the new services and their possible benefits.

\section{References}

Bouwman, H., Carlsson, C., Molina-Castillo, F. \& Walden, P. (2007). "Barriers and Drivers in the Adoption of Current and Future Mobile Services in Finland,"
Telematics and Informatics, vol.24, no.2, pp.145-160.

Brown, I., Cajee, Z., Davies, D. \& Stroebel, S. (2003). "Cell Phone Banking Predictors of Adoption in South Africa - An Exploratory Study," International Journal of Information Management, vol.23, no.3, pp.381-393.

Brown, I., Gordon, C., Janik, N. \& Meyer, M. (2005). "Investigating Adoption/NonAdoption of Cell Phones for Financial Transactions in South Africa," Proceedings of the 16th Australasian Conference on Information Systems, 20th November-2nd December 2005, Sydney; Australia.

Business Monitor International (2009). "South Africa Telecommunications Report Q1, 2009," Business Monitor International, ISSN: $1748-4820$.

Chen, L. \& Frolick, M. N. (2004). "Assessing M-Commerce Opportunities," Information Systems Management, vol. 21 no.2, pp.5361.

Converging Communications. (2005). "South Africa's Definitive Guide to the Convergence of Information and Communication Technologies," South Africa: ITWeb Informatica.

Doens, M. (2005). The Current State of B2B E-Marketplace Adoption in South African Agriculture. Masters thesis, Cape Town; Department of Information Systems, Faculty of Commerce, UCT.

E-business handbook. (2006). 'The EBusiness Handbook: The Review of Innovation at Work in South African Business,' Cape Town, South Arica: Trialogue.

Global Network Rollout Status. (2005). "3G South Africa - 3G/UMTS/HSDPA Network Rollout Status," Statistics and network Information. [Online], [Retrieved June, 2008],

http://www.3g.co.za/content/view/23/33.

Goldstuck, A. (2005). 'The Goldstuck Report: Mobile banking in South Africa,' [Online]" [Retrieved April, 2006], 
http://www.theworx.biz/MOBILE05.html

Gordon, C., Janik, N. \& Meyer, M. (2004). "The Non-Adoption of Cell Phones for Financial Transactions - A Qualitative Study," Empirical Report, Cape Town; Department of Information Systems, Faculty of Commerce, UCT.

Hislop, R. (2004). "Hobbled by Ball and Value Chain," ITWeb Brainstorm.

Hung, S.Y., Ku, C.Y. \& Chang, C.M. (2003). "Critical Factors of WAP Services Adoption: an Empirical Study," Electronic Commerce Research \& Applications, vol. 2, no. 1, pp. 42-60. International Telecommunication

Joubert J. \& Van Belle J.P. (2009). "The Importance of Trust and Risk in MCommerce: A South African Perspective," Proceedings of the Pacific Asia Conference, Hyderabad, India. Available AIS Electronic Library

http://aisel.aisnet.org/pacis2009/96.

Kaasinen, E. (2005). "User Acceptance of Mobile Services- Value, Ease of Use, Trust and Ease of Adoption," Finland: VTT publications. [Online], [Retrieved June, 2006],

http://www.vtt.fi/inf/pdf/publications/20 05/P566.pdf

Manjoo, S. \& Kankwenda, G. (2007). 'The Uses and Gratifications of Mobile Internet in South Africa,' Empirical Research, Cape Town; Department of Information Systems, Faculty of Commerce, University of Cape Town.

Marrakech, M. (2002). "Partnership Framework for ICT Infrastructure Development in Africa: Executive Summary," International Telecommunication Union. [Online], [Retrieved June, 2008], http://www.itu.int/ITUD/afr/projects/doc uments/ITU_NEPAD_Executive_Summary_f inal_En.pdf

Massey, A. P., Ramesh, V. \& Venkatesh, V. (2003). "Understanding Usability in Mobile Commerce," Communications of the ACM, vol.46, no.12, pp.55-56.
Mattila, M. \& Mari, S. (2004). "Mobile Banking and Consumer Behaviour: New Insights into the Diffusion Pattern," Journal of Financial services Marketing, vol.8, no.4, pp 354- 366

Minges, M. (1999). "Mobile Cellular Communications in the Southern African Region," Telecommunications Policy, vol. 23, pp.585-593.

Minges, M., Gray, V. \& Tayob, M. (2004). "The Fifth Pillar: Republic of Mauritius ICT Case Study," International Telecommunication Union. [Online],

[Retrieved June, 2008], http://www.itu.int/itudoc/gs/promo/bdt/ cast_int/86187.html

Ramburn, A. (2007). 'Understanding Use and Adoption of Mobile Data Services in Two African Countries,' Masters Degree in Information Systems, Cape Town; Department of Information Systems, Faculty of Commerce, University of Cape Town.

Rouvinen, P. (2004). 'Diffusion of Mobile Telephony: Are Developing Countries Different?,' Proceedings of UNU- WIDRER conference, 2004; Finland.

Scott, N., Batchelor, S., Ridley, J. \& Jorgensen, B. (2004). "The Impact of Mobile Phones in Africa," The Commission for Africa. [Online], [Retrieved June, 2007], http://www.commissionforafrica.org/fren ch/report/background/scott_et_al_backgro und.pdf

Singh, I. K. (2003). 'Mobile Commerce: Usage and Usability,' Proceedings of the 4th Word Wide Web Applications Conference, 4-6th September, University of Stellenbosch, Cape Town; South Africa.t

Steenkamp, W. (2005). "Cellphone Charges Far Too High: Report," Weekend Argus, September 2005.

Tarasewich, P. (2003). "Designing Mobile commerce Applications," Communications of the ACM, vol.46, no.12, pp.57-60. 
Turban, E., McLean, E., Wetherbe, J., Bolloju, N. \& Davison, R. (2002). 'Information Technology for Management,' USA: John Wiley \& Sons, Inc.

Union. (2007). "Telecommunication/ICT Markets and Trends in Africa," [Online], [Retrieved September, 2008], http://www.itu.int/ITUD/ict/statistics/ma terial/af_report07.pdf

Van Wyk, S. \& Van Belle, J.-P. (2005). "Adoption Factors for Mobile Gaming in South Africa," Proceedings of the 5th International Business Information Management Conference (IBIMA), 13-15th December 2005, Cairo; Egypt.

Vecchiatto, P. (2005). "Pricey Broadband Hampers Development," IT Web, October 2005.

Vodacom (2009). 'Vodacom Group Limited: Annual Financial Results,' [Online], [Retrieved May, 2010], http://www.sharenet.co.za/v3/sens_displa y.php?tdate $=20090519080002 \&$ seq $=865$

World Bank. (2007). 'GNI Per Capita 2006, Atlas method and PPP,' World Development Indicators database.[Online], [Retrieved July, 2008], http://siteresources.worldbank.org/DATA STATISTICS/Resources/GNIPC.pdf 